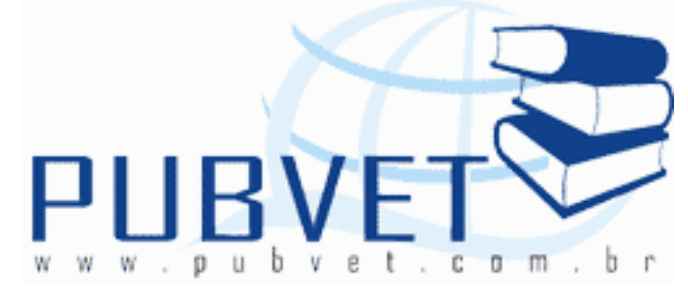

PUBVET, Publicações em Medicina Veterinária e Zootecnia.

\title{
Impactos econômicos da produção orgânica animal em unidades familiares nas regiões semiárida brasileira e toscana italiana
}

Andréa Cristina Capriata Silva ${ }^{1}$, João Paulo Guimarães Soares ${ }^{2}$, Hilton Felipe Marinho Barreto ${ }^{3}$, Andrea Martini ${ }^{4}$ e Débora Andréa Evangelista Façanha ${ }^{5}$

1 Doutoranda em Parasitologia UFPEL, Pelotas-RS, Brasil - Bolsista FAPERGS/CAPES; Email: deiavet@hotmail.com

2 Pesquisador A Embrapa Cerrados, Planaltina-DF, Brasil;

Email: jp.soares@embrapa.br

${ }^{3}$ Docente IFRN, Apodi-RN, Brasil; Email: felipe.barreto@ifrn.edu.br

${ }^{4}$ Docente UNIFI, Florença - Itália; Email: andrea.martini@unifi.it

${ }^{5}$ Docente UFERSA, Mossoró-RN, Brasil; Email: debora ufersa@hotmail.com

\section{Resumo}

O objetivo deste trabalho foi avaliar os impactos econômicos do manejo orgânico de animais em unidades de produção familiares no semiárido brasileiro e na região toscana italiana. Foram utilizados questionários para coleta de informações que avaliavam a receita relativa global anual, despesa relativa global anual e ganho líquido relativo anual das propriedades avaliadas. $\mathrm{Na}$ composição dos índices foram levadas em consideração tanto as vendas, quanto a parcela da produção destinada ao autoconsumo ou ao reaproveitamento, bem como as despesas referentes às atividades pecuárias. Observou-se um ganho líquido médio na receita das unidades familiares nos 
ambos países avaliados. Antes da adoção da tecnologia na região semiárida brasileira o ganho médio era de $\mathrm{R} \$ 1.644,06$ e após o implemento tecnológico passou a ser de $R \$ 5.527,53$, já na região toscana italiana antes da adoção da tecnologia o ganho médio era de $\mathrm{R} \$ 615.565,61$ e após o implemento tecnológico passou a ser de $R \$ 1.006 .330,14$. Após a implantação do manejo nas unidades avaliadas na região semiária houve uma maior diversificação das atividades pecuárias, incentivando principalmente a ovinocultura e a apicultura. O que difere da região toscana, onde entre a maioria dos produtores avaliados praticavam apenas a bovinocultura. O presente estudo mostra que a utilização da produção orgânica animal teve grande importância para o incremento monetário nas propriedades avaliadas, mostrando-se como uma atividade viável economicamente e sendo indicada para a agricultura familiar.

Palavra-chave: produção orgânica, agricultura sustentável, ganhos líquidos, receita, rentabilidade, sustentabilidade econômica

\title{
Economic impacts by the animal organic production in familiar units in the western potiguar - Brazil and tuscan region of Italy
}

\begin{abstract}
The objective of this study was evaluated the economic impacts by the organic production in units of familiar production in the western potiguar - Brazil and tuscan region of Italy. Questionnaires were used for information collection of the referring the annual global relative prescription, annual global relative expenditure and annual relative liquid profit in properties valued. The indices was composed using the sales had been taken, how much the parcel of the production destined to themselves and recicle, as well as expenses related to livestock. Was observed a average liquid profit in units of familiar in both countries evaluated. Before the adoption of technology in the western potiguar- Brazil the average liquid profit was $R \$ 1,644.06$ and after the implement technological rose to $R \$ 5,527.53$, as the tuscan region of Italy
\end{abstract}


before the adoption of the technology the average liquid profit was $R \$$ $615,565.61$ and after the implement technological rose to $R \$ 1,006,330.14$. After the handling implantation in the units evaluated in the western potiguarBrazil was had a bigger diversification of the cattle breeding business, mainly stimulating the ovinocultura and the beekeeping. That's different in the tuscan region of Italy, where among the most evaluated producers practiced just cattle production. These results show that the use of the handling contributed for the monetary increment in the familiar units studied, configuring itself as generating of positive impact $\mathrm{e}$, therefore, indicated for application for familiar agriculture.

Keywords: organic production, sustainable agriculture, profits, prescription, yield, economic support

\section{INTRODUÇÃO}

A agricultura moderna não tem se mostrado sustentável. O Surgimento de uma nova agricultura "agroecologia" tem apresentado novas perspectivas para viabilizar a produção respeitando o meio ambiente e a vida dos produtores. Esse tipo de agricultura aponta o caminho da sustentabilidade econômica, social e ambiental. A necessidade de conciliar o crescimento econômico do país com a conservação dos recursos naturais é uma tarefa que impõe grande desafio, uma vez que os superávits na balança comercial dependem da exportação de produtos agrícolas cultivados em grande. (IBGE, 2004).

A crise sócio-ambiental deste final de século colocou em xeque as bases teóricas e metodológicas que sustentaram o estabelecimento do atual modelo de crescimento econômico e sua reiterada inobservância dos limites impostos pela natureza, especialmente no que concerne aos meios de produção. Diante da complexidade e gravidade do momento atual, faz-se necessária uma mudança na estrutura dos meios de produção conciliando-os com o desenvolvimento sustentável local, seja urbano ou rural. Nesse contexto o 
ideal de sustentabilidade apoiado nos princípios de uma agricultura sustentável exige entender a agricultura como um processo de construção social e não simplesmente como a aplicação de algumas tecnologias, daí a importância do desenvolvimento sustentável no meio rural. Isto é, ajudar no direcionamento de ações e atividades que promovam novos estilos de desenvolvimento e de agricultura, que respeitem não só as condições específicas de cada agroecossistema, mas também a preservação da biodiversidade e da diversidade cultural (SEVILLA GUZMÁN, 1999).

O desenvolvimento sustentável possui basicamente duas vertentes: uma que analisa o fenômeno dentro da esfera da economia, pensando a natureza como bem de capital, e a outra, que considera os aspectos econômicos, sociais e ambientais, estabelecendo desafios importantes para muitas áreas do conhecimento ABREU (2001).

Agricultura Sustentável pode ser definida como uma agricultura ecologicamente equilibrada, economicamente viável, socialmente justa, humana e adaptativa (Reijntjes et al, 1992).

A agricultura orgânica vem se destacando como uma alternativa aos tradicionais usos agrícolas, uma vez que é baseada em princípios ecológicos e de conservação dos recursos naturais. Este sistema de produção teve origem nos anos 30, sendo seu fundador Sir Albert Howard, para quem "a verdadeira fertilidade dos solos deve estar assentada sobre um amplo suprimento de matéria orgânica e principalmente na manutenção de elevados níveis de húmus no solo" (HOWARD, 2007).

A produção orgânica animal vem se mostrando como uma atividade relativamente nova no mercado, conquistando a cada dia mais consumidores. O manejo orgânico animal na Itália apresenta a sua legislação bem delineada e difundida entre os agricultores e consumidores, isso faz com que haja uma sazonalidade dos produtos no mercado e preços tabelados. Já no Brasil a legislação é bastante nova o que dificulta a compreensão de muitos agricultores e consumidores, fazendo com que os produtos nem sempre possuam uma certa instabilidade na sazonalidade e nos preços. 
Em levantamentos feitos em propriedades com sistemas de produção orgânica de leite, por exemplo, este, não chegou a $0,1 \%$ do total produzido no Brasil, que foi em 2004, aproximadamente 23 bilhões de litros/ano. O leite orgânico produzido (certificado) no Brasil alcança até três vezes o valor do produto convencional, se vendido diretamente ao consumidor (AROEIRA et al, 2005, 2006). Quando vendido a cooperativas/laticínios, o produto é comercializado com $50 \%$ de acréscimo. Porém a pequena escala mesmo com valores superiores pagos ao produtor não compensa os custos.

Sabe-se que para haver sucesso e manutenção do agricultor na atividade é indispensável que haja um retorno financeiro satisfatório. Não existem muitos trabalhos na literatura que comprovem a sustentabilidade econômica da produção orgânica animal. Portanto é imprescindível que se avaliem os impactos econômicos advindos deste sistema de produção em unidades familiares para que sejam identificados os pontos altos e baixos da economia nesta atividade para que sejam corrigidos os erros e potencializar os acertos. Com isso irá favorecer a inserção desses produtores no mercado globalizado, que está cada vez mais competitivo.

\section{OBJETIVO GERAL}

Avaliar os impactos econômicos da produção orgânica animal em unidades de produção familiar no semiárido brasileiro e na região toscana da Itália.

\section{OBJETIVOS ESPECÍFICOS}

$\checkmark$ Mensurar o incremento da receita advinda das atividades pecuárias das famílias envolvidas com esse manejo;

$\checkmark$ Analisar a influência da produção orgânica na diversificação das atividades pecuárias das unidades familiares; 
$\checkmark$ Avaliar a receita relativa global total, despesa relativa e ganhos líquido relativos advindos das atividades pecuárias nas unidades familiares que utilizam a produção orgânica animal.

\section{METODOLOGIA}

\subsection{Local, período e caracterização das unidades familiares}

A primeira parte do experimento foi realizada na região semiárida brasileira, no município de Apodi - Rio Grande do Norte. Onde foram realizada as coletas dos dados no ano de 2009. Foram avaliadas sete unidades produtivas familiares. Todos os agricultores selecionados na região semiárida realizavam prioritariamente atividades de caprinocultura e apicultura, utilizando animais SRD (Sem Padrão de Raça Definida) e de dupla aptidão, ou seja, corte e leite, com exceção de quatro agricultores que também tinham atividades de produção de ovinos e três com bovinos e aves.

Posteriormente foi realizada a segunda parte do experimento, na região toscana da Itália. Sendo as coletas realizadas as coletas dos dados no ano de 2010. Onde também foram entrevistadas sete unidades produtivas familiares. A primeira e a sexta unidade produtivas avaliadas eram especialistas na produção de bovinos da raça Limousine. Já a segunda propriedade avaliada possuía a criação de bovinos da raça Limousine e ainda a criação de ovinos da raça Bergamasca. O terceiro agricultor possuía na propriedade a criação de bovinos da raça Frisona. A quarta propriedade avaliada possuía como atividade principal a ovinocultura, com a produção da raça Sarda. O quinto agricultor entrevistado possuía a criação de bovinocultura e caprinocultura. As raças de bovinos eram Limousine e Chianina. Já raça de caprino produzida nesta propriedade é a Incroci. O sétimo e último agricultor avaliado realizava a atividade de bovinocultura e a raça utilizada é a Frisona.

O estudo avaliou um total de 14 propriedades em ambos países, onde foram feitos levantamentos das propriedades selecionadas através de 
questionários para obtenção de informações relacionadas a características ambientais dos agricultores antes, quando realizavam a agricultura convencional e depois de se converteram para a produção orgânica animal. 0 número de propriedades avaliadas foram selecionadas conforme a metodologia validada segundo Irias et. al. (2004).

\subsection{Instrumento de coleta e formação dos índices}

\subsubsection{Receita global anual}

Foram utilizados questionários onde possuíam questões referentes a produção dos diversos produtos pecuários e que foram somadas para formar a receita bruta anual das famílias, antes e depois da implantação da tecnologia. Este procedimento foi realizado em dois momentos distintos e independentes em cada um dos países avaliados. Para a compilação dos dados só foram levadas em consideração às rendas atividades pecuárias orgânica (caprinocultura, ovinocultura, bovinocultura, avicultura e apicultura):

$$
\mathrm{RA}=(Q p v n+Q p c n+Q p a n) \times P p n)
$$

Onde: RA - Receita anual da atividade;

$Q p v$ - Quantidade de produtos vendidos anualmente;

$Q p c$ - Quantidade de produtos consumidos anualmente;

Qpa - Quantidade de produtos aproveitados anualmente;

$P p$ - Preço unitário de venda do produto;

$n$ - Representa os diversos produtos obtidos pelas atividades pecuárias;

A receita global é dada através do valor de todas as vendas efetuadas, onde leva em consideração o volume de vendas e os preços unitários de cada um dos produtos comercializados (MATTOS, 1999 apud CALLADO; ALBUQUERQUE; SILVA, 2007). Neste caso, além dos produtos comercializado, também foram incluídos os produtos utilizados para o suprimento alimentar da própria família (autoconsumo), e ainda os produtos que foram reaproveitados na própria propriedade rural, pois passaram a ser considerado receita a partir 
do momento em que deixaram de ser adquiridos fora da unidade familiar, conforme representado na expressão a seguir:

$$
\mathrm{RTg}=R A 1+R A n
$$

Onde: RTg - Receita global anual;

$R A$ - Receita anual da atividade;

$n$ - Representa as diversas atividades pecuárias.

Em cada um dos países avaliados foram calculadas as receitas globais em dois momentos, sendo o primeiro referente ao ano anterior a implantação da atividade orgânica e outro após o implemento da atividade, buscando uniformizar as receitas. Foram realizados os cálculos que permitiram se estimar o ganho bruto referente a esses dois momentos, conforme a expressão abaixo:

$$
\mathrm{Gb}=R T g \text { (depois) }-R T g \text { (antes) }
$$

\subsubsection{Despesa global anual}

Foram levantadas as despesas dos custos variáveis com as atividades pecuárias para se estimar a margem do ganho líquido, onde foi utilizado um formulário que buscou quantificar os itens orçamentários comumente utilizados pelos agricultores nos seus sistemas de produção de animais orgânicos em ambos países.

Optou-se por utilizar a despesa global, que corresponde ao custo agregado total do empreendimento. Isso deve-se ao fato de que a maioria dos agricultores familiares não possuem o hábito de fazer anotações necessárias para que se possa analisar os custos da produção individualmente em cada atividade (CALLADO; ALBUQUERQUE; SILVA, 2007), conforme esquematizado na expressão abaixo: 


$$
\mathrm{DTg}=(Q c d 1 \times P c d 1)+(Q c d n \times P c d n)
$$

Onde: DTg - Despesa global anual;

Qcd - Quantidade do componente de despesa;

Pcd - Preço unitário do componente de despesa;

$n$ - Representa os diversos componentes de despesa;

\subsubsection{Ganho líquido anual}

Nos sistemas de produção orgânico familiar a remuneração dos agricultores é dada pela diferença entre a receita obtida pela vendas dos produtos e às despesas referentes à sua produção e comercialização. Com isso a manutenção das famílias advém do ganho líquido, que é formado pelo saldo obtido pelo conjunto de atividades desenvolvidas na unidade produtiva. Neste estudo o levantamento do ganho líquido anual não possuiu o viés da identificação das atividades que, por ventura, não estavam sendo lucrativas ou que apresentavam baixo desempenho, pelo contrário buscou averiguar a remuneração líquida da unidade familiar, antes e depois da adoção da tecnologia da produção orgânica animal. Então, de posse das receitas e do custo global referente às atividades pecuárias realizaram-se os cálculos necessários para a obtenção da margem líquida de remuneração, conforme descrito abaixo:

$$
\mathrm{GL}=(R T g(\text { depois })-D T g(\text { depois }))-(R T g(\text { antes })-D T g(\text { antes }))
$$

Onde: GL - Ganho líquido anual;

$R T g$ (depois) - Receita global anual - depois da implantação da tecnologia;

$D T g$ (depois) - Despesa global anual - depois da implantação da tecnologia;

$R T g$ (antes) - Receita global anual - antes da implantação da tecnologia;

DTg(antes) - Despesa global anual - antes da implantação da tecnologia. 
Nos dados obtidos na Itália também foram empregados os mesmos cálculos aplicados no Brasil. Porém foi necessária a conversão da moeda local, o euro em real. Onde a conversão foi realizada com o auxilio da tabela de conversão do Banco Central do Brasil, com a cotação de 2,2754 para o dia 03 de fevereiro de 2011.

\section{RESULTADOS E DISCUSSÃO}

Analisando a Tabela 9 podemos observar que as unidades produtivas avaliadas na região semiárida brasileira após a adoção do manejo orgânico apresentaram uma maior diversificação nas atividades produtivas. A apicultura e a ovinocaprinocultura foram as atividade que se destacaram mais entre as unidades produtivas avaliadas. Para Rabelo; Pires; Xavier (2002) esse comportamento é típico de agricultura familiar, que diversifica para diminuir os riscos.

Todas as atividades após a adoção da tecnologia tiveram um aumento na receita relativa global anual e com isso sofreram uma grande influência da produção orgânica animal (Tabela 9). Este incremento deve-se principalmente ao fortalecimento da principal atividade pecuária da região semiárida brasileira que é a caprinocultura, que está presente em 6 das 7 unidades avaliadas e após a adoção da tecnologia a atividade apresentou um maior ganho de receita em todas as unidades produtivas.

O manejo orgânico na região semiárida favoreceu a produção de esterco que foi utilizado para adubação das pastagens o que permitiu na maioria dos casos uma maior disponibilidade de alimentos e consequentemente o aumento do rebanho. E ainda alguns agricultores deixaram de adquirir esterco de outras propriedades o que diminuiu a despesa global anual e incrementou o ganho líquido anual.

O sucesso da apicultura na região semiárida brasileira está relacionado a atividade do manejo orgânico, pois houve uma maior preservação do meio ambiente, favorecendo a fauna e a flora de espécies locais, permitindo floradas 
SILVA, A.C.C. et al. Impactos econômicos da produção orgânica animal em unidades familiares nas regiões semiárida brasileira e toscana italiana. PUBVET, Londrina, V. 7, N. 5, Ed. 228, Art. 1508, Março, 2013.

mais diversificadas e bem distribuídas, principalmente pela participação de outras essências nativas que não tinham oportunidade de florescer, e com isso favoreceu um grande incremento na receita global anual desses produtores.

O agricultor 3 das unidades avaliadas no Brasil após a implementação da tecnologia possuiu o maior ganho líquido anual entre as unidades avaliadas no valor de $\mathrm{R} \$ 13.944,67$ e antes a sua renda era 0 . Em segundo lugar em termos de ganho líquido temos o agricultor 2 com o valor de $R \$ 8.450,60$ após a implementação da tecnologia e possuía um lucro anual antes da utilização da tecnologia de $\mathrm{R} \$-495,00$ (Tabela 9 ).

Tabela 9. Impacto econômico da produção orgânica em unidades produtivas familiares da região semiárida brasileira.

\begin{tabular}{|c|c|c|c|c|c|c|}
\hline \multirow[b]{5}{*}{ Agricultor 1} & Atividade & Período & $\begin{array}{l}\text { Receita } \\
\text { anual da } \\
\text { atividade } \\
(\mathrm{R} \$)\end{array}$ & $\begin{array}{l}\text { Receita } \\
\text { global anual } \\
(\mathrm{R} \$)\end{array}$ & $\begin{array}{l}\text { Despesa } \\
\text { global } \\
\text { anual }(R \$)\end{array}$ & $\begin{array}{l}\text { Ganho líquido } \\
\text { anual }(R \$)\end{array}$ \\
\hline & Caprinocultura & Antes & $2.856,50$ & $2.856,50$ & $1.020,00$ & $1.836,50$ \\
\hline & & Depois & $3.328,00$ & $3.443,40$ & $1.987,00$ & $1.456,40$ \\
\hline & Avicultura & Antes & 0,00 & & & \\
\hline & & Depois & $1.115,40$ & & & \\
\hline \multirow[b]{8}{*}{ Agricultor 2} & Caprinocultura & Antes & 600,00 & 600,00 & $1.095,00$ & $-495,00$ \\
\hline & & Depois & $7.384,00$ & $12.461,10$ & $4.010,50$ & $8.450,60$ \\
\hline & Avicultura & Antes & 0,00 & & & \\
\hline & & Depois & 0,00 & & & \\
\hline & Bovinocultura & Antes & 0 & & & \\
\hline & & Depois & $2.423,50$ & & & \\
\hline & Apicultura & Antes & 0,00 & & & \\
\hline & & Depois & $2.653,60$ & & & \\
\hline \multirow[b]{8}{*}{ Agricultor 3} & Avicultura & Antes & 0,00 & 0,00 & 0,00 & 0,00 \\
\hline & & Depois & 0,00 & $17.748,67$ & $3.804,00$ & $13.944,67$ \\
\hline & Caprinocultura & Antes & 0,00 & & & \\
\hline & & Depois & $9.855,50$ & & & \\
\hline & Ovinocultura & Antes & 0 & & & \\
\hline & & Depois & 360 & & & \\
\hline & Bovinocultura & Antes & 0 & & & \\
\hline & & Depois & $7.533,17$ & & & \\
\hline
\end{tabular}


SILVA, A.C.C. et al. Impactos econômicos da produção orgânica animal em unidades familiares nas regiões semiárida brasileira e toscana italiana. PUBVET, Londrina, V. 7, N. 5, Ed. 228, Art. 1508, Março, 2013.

\begin{tabular}{|c|c|c|c|c|c|c|}
\hline \multirow[b]{8}{*}{ Agricultor 4} & Avicultura & Antes & 0 & $6.708,80$ & $2.082,00$ & $4.626,80$ \\
\hline & & Depois & 0 & $8.122,75$ & $1.478,00$ & $6.644,75$ \\
\hline & Caprinocultura & Antes & $2.668,80$ & & & \\
\hline & & Depois & $3.811,75$ & & & \\
\hline & Bovinocultura & Antes & $2.920,00$ & & & \\
\hline & & Depois & $3.611,00$ & & & \\
\hline & Apicultura & Antes & $1.120,00$ & & & \\
\hline & & Depois & 700,00 & & & \\
\hline \multirow[b]{6}{*}{ Agricultor 5} & Caprinocultura & Antes & 450 & $2.018,62$ & 246 & $1.772,62$ \\
\hline & & Depois & 0 & $2.870,00$ & 246 & $2.624,00$ \\
\hline & Ovinocultura & Antes & 0 & & & \\
\hline & & Depois & 320 & & & \\
\hline & Apicultura & Antes & $1.568,62$ & & & \\
\hline & & Depois & $2.550,00$ & & & \\
\hline \multirow[b]{6}{*}{ Agricultor 6} & Avicultura & Antes & 0 & $1.640,00$ & 280 & $1.360,00$ \\
\hline & & Depois & 0 & $10.076,00$ & 560 & $9.516,00$ \\
\hline & Caprinocultura & Antes & $1.640,00$ & & & \\
\hline & & Depois & $2.376,00$ & & & \\
\hline & Apicultura & Antes & 0 & & & \\
\hline & & Depois & 7.700 & & & \\
\hline \multirow[b]{8}{*}{ Agricultor 7} & Avicultura & Antes & 0 & $2.802,50$ & 395 & $2.407,50$ \\
\hline & & Depois & 0 & $1.889,80$ & $5.833,50$ & $-3.943,70$ \\
\hline & Caprinocultura & Antes & 942,5 & & & \\
\hline & & Depois & $1.106,40$ & & & \\
\hline & Bovinocultua & Antes & $1.860,00$ & & & \\
\hline & & Depois & 0 & & & \\
\hline & Apicultura & Antes & 0 & & & \\
\hline & & Depois & 783,4 & & & \\
\hline
\end{tabular}

O que pode explicar estes impactos econômicos substanciais é o fato de que o período de implantação do manejo (em 2002 - agricultor 3 e 2003 agricultor 2) se deu muito próximo ao da liberação do crédito do PRONAF, que ocorreu em 2001. Esse fator contribuiu para que as receitas auferidas antes do manejo coincidissem com as de antes do acesso ao crédito e, portanto, bem inferiores às obtidas no momento da coleta das informações. A justificativa apresentada não invalida os benefícios gerados pelas práticas do manejo orgânico animal, muito pelo contrário, mostra o que é indispensável para que 
haja um crescimento econômico sustentável é necessário haja equilíbrio entre as práticas agrícolas e o meio ambiente.

Em contrapartida encontramos os agricultores 7 e 1 do Brasil foram os que sofreram os menores impactos econômicos advindos da tecnologia. 0 agricultor 1 tinha um ganho líquido anual de $R \$ 1.836,50$ antes da adoção da tecnologia e após o uso da mesma teve um ganho líquido anual no valor de $\mathrm{R} \$ 1.456,40$ (Tabela 9). Já o agricultor 7 possuía ganho líquido anual de $\mathrm{R} \$ 2.407,50$ e após a adoção da tecnologia obteve um ganho líquido anual de $3.943,70$, ou seja um valor negativo (Tabela 9). Esse baixo impacto econômico está relacionado a baixa variação no rebanho e principalmente porque esses produtores ainda estão realizando benfeitorias em suas propriedades, devido aos prejuízos causados pelas chuvas de 2009.

Observa-se que após o manejo orgânico houve um aumento nas despesas da maioria das unidades produtivas na região semiárida brasileira. 0 agricultor 7 apresentou a maior despesa global anual no valor de $R \$ 5.833,50$. Isso deve-se ao produtor ainda está recuperando seu pasto e a sua propriedade da enchente que ocorreu no ano de 2009.

No caso do agricultor 5 das unidades avaliadas no Brasil, foi observado que não houve alterações na despesa anterior e posterior ao uso da produção orgânica animal, mantendo - se em torno de R\$246 (Tabela 9). Este valor é atribuído ao fato desta unidade de produção não ter alterações relevantes no seu rebanho em função da produção orgânica, houve apenas a substituição da atividade caprina (22 cab.) pela ovina (32 cab.) e um aumento de apenas duas colméias do seu apiário que não geraram despesas extras.

Contrapondo aos demais estabelecimentos da região semiárida brasileira, tem - se o agricultor 4 que teve as suas despesas relativas reduzidas após a utilização da produção orgânica animal, onde antes da adoção tinha uma despesa global anual de $\mathrm{R} \$ 2.082,00$ e após a adoção da tecnologia passou a ter uma despesa de $R \$ 1.478,00$ (Tabela 9). Esse fato ocorreu devido o agricultor após a adoção da produção orgânica passou a possuir um esterco de 
melhor qualidade para adubar a sua pastagem e com isso conseguiu reduzir as compras com suplemento para os animais na época da seca.

Cavalcante et al. (2007) avaliando o modelo experimental de produção orgânica de cabritos para unidades familiares do sertão pernambucano e baiano do São Francisco encontrou que os custos totais médios de produção foram de $\mathrm{R} \$ 4,95 / \mathrm{Kg}$ de carne, tendo os custos com concentrado representado $56 \%$ dos Custos Operacionais Efetivos, indicando que há necessidade de redução desses custos. Os preços médios pagos pelo mercado variam de $R \$$ 5,00 a R4 6,00/ kg de carne, representando que o modelo foi economicamente viável. Mostrando-se eficiente, técnica e economicamente, nos dois anos avaliados.

Na região toscana italiana a maioria das unidades produtivas possuíam apenas 1 ou 2 atividade produtiva. Todos os agricultores criavam bovinos e alguns diversificavam na criação de ovinos. E apenas 1 agricultor praticava a caprinocultura. Os agricultores que tinham como atividade a avicultura em todos os casos eram apenas para suprir as necessidades familiares. A bovinocultura foi a atividade responsável por incrementar a receita global anual de todas as propriedades avaliadas (Tabela 10). Isso mostra que os agricultores nessa região da Itália praticam a monocultura e preferem se especializar apenas na criação de uma espécie bovina.

O agricultor 1 apresentou o maior índice de ganho líquido anual após a implantação da tecnologia no valor de $R \$ 2.291 .755,60$ (Tabela 10). Onde somente com a produção orgânica de bovinos o agricultor possuiu os maiores índices de ganho líquido anual, isso deve-se a grande estabilidade nos preços dos produtos orgânicos e ainda possuir um mercado consumidor assíduo.

Em segundo lugar em relação ao ganho líquido anual temos o agricultor 4 que antes da adoção da tecnologia apresentava-se em prejuízo com a realização da atividade no valor de $R \$-41.985,50$ e após a adoção da tecnologia houve um incremento no seu ganho líquido anual de $61.770,47$ (Tabela 10). 
O agricultor 6 não possuiu diferença no ganho líquido anual permanecendo na casa dos $\mathrm{R} \$ 571.034,38$ (Tabela 10) mesmo depois da adoção da tecnologia. Já os agricultores 2,3 e 5 possuíram um pequeno aumento no ganho líquido anual, $R \$ 1.353 .316,91, R \$ 749.120,84$ e $R \$$ $1.467 .382,71$, respectivamente (Tabela 10 ). Isso deve-se ao fato do número do seu rebanho não ter sofrido alterações mesmo após a implantação da tecnologia.

O agricultor 7 possuiu uma redução no ganho líquido anual após o uso da produção orgânica animal no valor de $R \$ 549.930,05$, sendo que antes da utilização do manejo orgânico o seu ganho líquido era de $R \$ 623.539,24$ (Tabela 10). Isso deve-se aos custos que o agricultor teve com reformas e contratação de mão-de-obra na propriedade, que deve ser revertido a curto prazo.

Na Europa os custos da produção animal se elevam devido ao valor da mão-de-obra braçal e especializada serem muito altos se comparados com países emergentes, tais como o Brasil.

$\mathrm{Na}$ maioria das propriedades não houve alteração na despesa global anual após a conversão em produção orgânica animal se comparadas com o período anterior (Tabela 10). Com exceção do agricultor 7 que houve um aumento nas despesas, que antes era $\mathrm{R} \$ 736.091,90$ e depois do uso da tecnologia passou a ser $\mathrm{R} \$ 809.701,09$ (Tabela 10). Fato que é explicado devido as reformas realizadas na propriedade e contratação de mão-de-obra.

\section{CONCLUSÃO}

A produção orgânica animal gerou grande contribuição para o incremento da receita das unidades familiares estudas em ambos países, gerando impacto econômico positivo.

O manejo orgânico apresenta-se como uma atividade viável economicamente, comparado com outros tipos de produção gera um ganho líquido bem acima da média de produção animal convencional. 
SILVA, A.C.C. et al. Impactos econômicos da produção orgânica animal em unidades familiares nas regiões semiárida brasileira e toscana italiana. PUBVET, Londrina, V. 7, N. 5, Ed. 228, Art. 1508, Março, 2013.

Os produtores da região toscana italiana apresentaram a monocultura, ou seja, a maioria só criava uma espécie animal. Já os agricultores do semiárido brasileiro necessitam diversificar a produção animal, criando diversas espécies de animais. Isto demonstra a instabilidade econômica na região semiárida, o que faz com que os produtores possam ter vários produtos em diferentes épocas do ano para haver uma maior segurança econômica, levando há melhores distribuições da renda ao longo do ano.

Tabela 10. Impacto econômico da produção orgânica em unidades produtivas familiares da região toscana italiana.

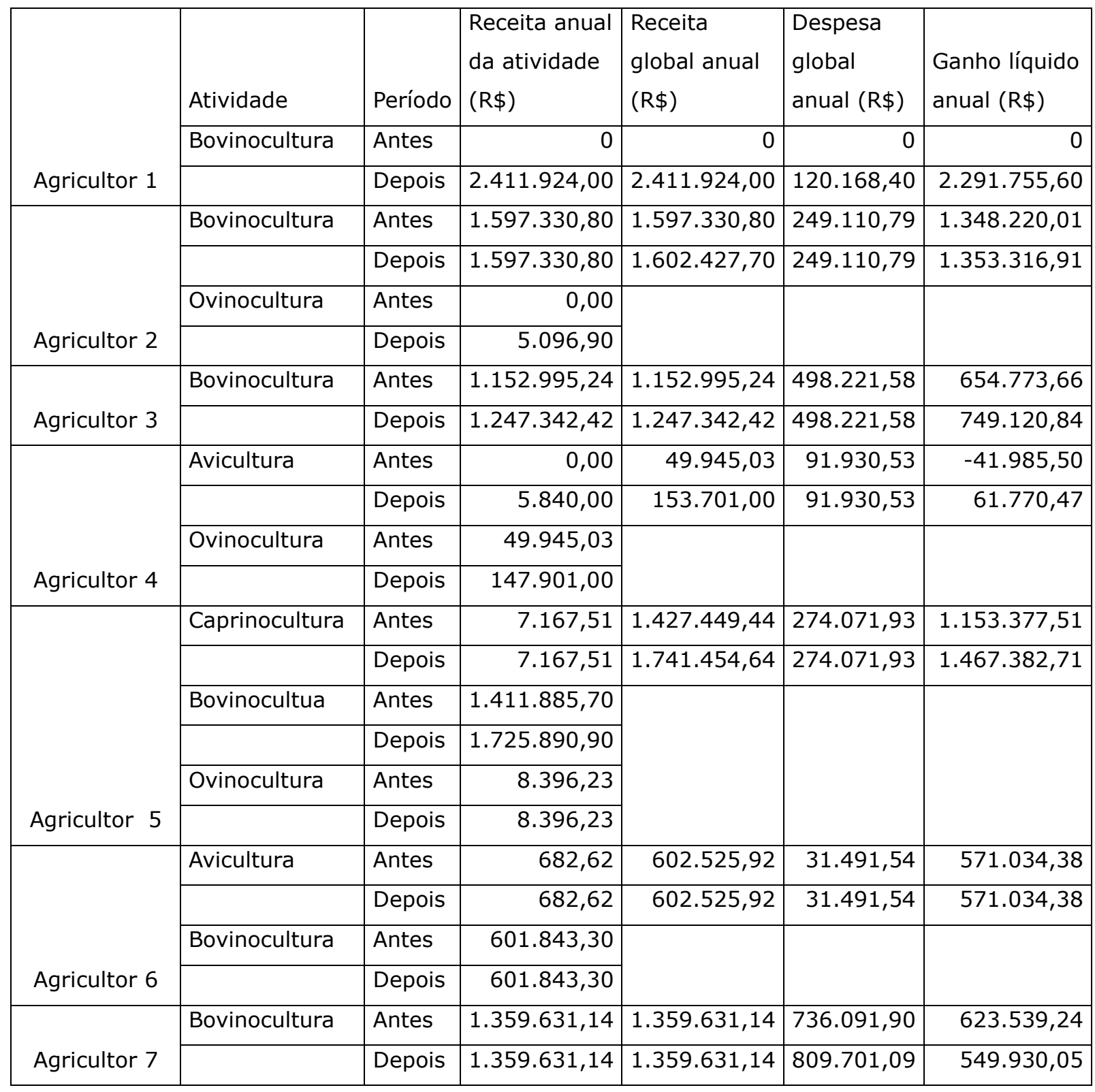




\section{REFERÊNCIAS BIBLIOGRÁFICAS}

ABREU, I. Agricultura sustentável. Cadernos de Direito UNIMEP, Piracicaba, v.1, p. 85-94, 2001.

AROEIRA, L. J. M.; PACIUllo, D. S. C.; FERnANDES, E. N.; PIRES, M.F.A.; MORENZ, M. F.; MACEDO, R. de O. Caracterização da produção orgânica de leite em algumas regiões do brasil. In: In: Reunião Anual da Associação Latino Americana de Produção Animal, 19, 2005. Anais... Tampico : ALPA, 2005.

AROEIRA, L. J.M; STOCK, L.A.; ASSIS, A. G.; MORENS, M.J.F.; ALVES, A. A.. Viabilidade da produção orgânica de leite no Brasil In: Reunião Anual da Sociedade Brasileira de Zootecnia, 43, 2006, João Pessoa. XLIII Reunião Anual da Sociedade Brasileira de Zootecnia. SBZ, 2006. p. CDROM.

CAllado, A. L. C; Albuquerque, J. L; SilvA, A. M. N da. Análise da relação custo/volume/lucro na agricultura familiar: o caso do consórcio mamona/feijão. Custos e @gronegócio on line, Recife, v. 3, n. 1, jan./jun. 2007. Disponível em: http://www.custoseagronegocioonline.com.br/principal.html>. Acesso em: 7 fev. 2011.

CAVALCANTE, A. C.; HOLANDA JúNIOR, E. V.; SOARES, J. P. G. Produção orgânica de caprinos e ovinos. Sobral: EMBRAPA Caprinos, 2007. 40 p. (Documentos, 69).

HOWARD, S. A. Um testamento agrícola. São Paulo: Expressão Popular, 2007. 360 p.

INSTITUTO Brasileiro de Geografia e Estatística - IBGE. Censo Agropecuário 1995- 2004. Rio de Janeiro: IBGE, 2004.

PIRES, A. C.; RABELO, R. R.; XAVIER, J. H. V. Uso potencial da análise do ciclo de vida (ACV) associada aos conceitos da produção orgânica aplicados à agricultura familiar. Cadernos de Ciência \& Tecnologia, Brasília, v.19, n. 2, p.149-178, maio/ago. 2002.

IRIAS, L.J.M.; RODRIGUES, G.S.; CAMPANHOLA, C.; KITAMURA, P.C.; RODRIGUES, I.; BUSCHINELLI, C.C. de A. Sistema de avaliação de impacto ambiental de inovações tecnológicas nos segmentos agropecuário, produção animal e agroindústria (Sistema AMBITEC). Jaguariúna: Embrapa Meio Ambiente, 2004. 8p (Embrapa Meio Ambiente. Circular técnica, 5).

REIJNTJES, C.; HAVERKORT, B.; WATERS-BAYER, A. Farming for the future: an introduction to low-external-input and sustainable agriculture. Leusden: Ileia, 1992. 250p.

SEVILLA GUZMÁN, E. Ética ambiental y Agroecología: elementos para uma estrategia desustentabilidad contra el neoliberalismo y la globalización económica. Córdoba: ISECETSIAM, Universidad de Córdoba, España, 1999. (mimeo). 